\title{
Evaluation of five commercial kits to detect dsDNA antibodies
}

\author{
S A McMillaN, ANNE C FAY Regional Immunology Laboratory, Belfast City Hospital, Belfast, \\ Northern Ireland
}

SUMMARY Experiments were performed to evaluate five commercial kit assays used for the detection of antibodies to dsDNA. The kits were compared using a performance index score as recommended by the guidelines of the European Committee for Clinical Laboratory Standards. The highest performance score was obtained using the radioimmunoassay from Immunodiagnostic Services Ltd, with the Amersham kit second, the immunofluorescence test using Crithidia luciliae third, the Walker ELISA kit fourth, and the haemagglutination assay fifth. The results showed that none of the kits was outstanding, each appeared to detect a different anti-DNA antibody type as different results were obtained using each kit in assays of quality control sera, linearity of the method, antibody detection in various patient groups, and interference by various substances.

It is suggested that laboratories using commercial assay kits for the detection of antibodies to dsDNA should decide which is the most appropriate to their particular needs and that a performance index scoring system may be useful in the comparison of assay evaluations between different laboratories.

The detection of antibodies to native DNA has become increasingly important in the evaluation of patients with systemic lupus erythematosus (SLE) ${ }^{1}$ and has recently been included in the revised diagnostic criteria of the American Rheumatism Association. ${ }^{2}$ Most clinical laboratories in the United Kingdom now measure these antibodies by means of commercially available kits rather than by in-house methods (personal communication, UK External Quality Assurance Scheme for autoimmune serology and special immunochemistry). Commercial laboratory assays are evaluated by their manufacturers but the results of laboratory precision and accuracy as determined by the manufacturer may not be reproducible in the routine laboratory.

We selected five kit assays which utilise the most common methods used for the detection of antibodies to dsDNA and evaluated them using the recommendations of the European Committee for Clinical Labortory Standards (ECCLS). ${ }^{3}$ This committee suggests the creation of a list of performance characteristics considered to be important for an individual laboratory. Each characteristic is given a weighting factor in line with its relative importance as judged by each laboratory and then scored according to the acceptability of the results. Thus a performance index score is obtained for each kit. We assessed two radioimmunoassay kits, one enzyme linked immunosorbent assay (ELISA), one passive haemagglutination assay and one indirect immunofluorescence assay. We present our interpretation of the ECCLS guidelines for the laboratory evaluation of these commercially available kits for the detection of antibodies to dsDNA.

\section{Material and methods}

The patients studied included 45 with severe SLE, most of whom had renal disease, who also satisfied the diagnostic criteria of the American Rheumatism Association, ${ }^{2} 41$ with seropositive rheumatoid arthritis (RA), and 120 blood donors. Clotted blood samples were obtained from all of them and the sera aliquoted and stored at $-70^{\circ} \mathrm{C}$ until testing.

\section{COMMERCIAL KITS}

Anti-dsDNA commercial kits were obtained and used before expiry date. The manufacturers' instructions for each kit were followed.

Anti-DNA kit (Amersham International plc, Amersham, England). This is a radioimmunoassay (RIA) based on the principle of the Farr technique. Patients' sera are diluted $1 / 10$, heat inactivated at $56^{\circ} \mathrm{C}$ for 30 minutes, and then incubated $(50 \mu \mathrm{l})$ with $50 \mu \mathrm{l}$ of ${ }^{125} \mathrm{I}$ labelled dsDNA first for one hour at $37^{\circ} \mathrm{C}$ then for 20 
24 hours at $2-4^{\circ} \mathrm{C}$. The bound antibody-dsDNA is then precipitated using ammonium sulphate and the precipitate settled by centrifugation. The amount of radioactivity in the precipitate after counting for 120 seconds with a gamma counter is used to construct a standard dose response curve using four reference standards. The test sera are read directly from the curve.

Gamma-B anti-ds DNA kit (Immunodiagnostics Services Ltd (IDS), Washington, England). This is an RIA based on the Farr technique. Patients' sera (neat) are first inactivated at $56^{\circ} \mathrm{C}$ for 30 minutes, then $50 \mu \mathrm{l}$ are incubated for 15 minutes at $37^{\circ} \mathrm{C}$ with $500 \mu \mathrm{l}^{125} \mathrm{I}$ labelled dsDNA. Antibody binding to the ${ }^{125} \mathrm{I}$ dsDNA is precipitated using saturated ammonium sulphate. The amount of radioactivity present in the dsDNA/ antibody complex is obtained by counting the precipitate for one minute using a gamma counter. The amount of dsDNA binding capacity in a serum is determined by comparison with a standard curve constructed using five reference standards.

MELISA ds DNA antibody kit (Walker Laboratories Ltd, Ely, England). This is a quantitative enzyme linked immunosorbent assay (ELISA) which uses a micropin system. Sera are first diluted 1:100 and dispensed $(100 \mu \mathrm{l})$ into wells of a microtitre plate. A template of pins coated with dsDNA is placed into the wells of the plate and incubated at room temperature for 30 minutes; the pins are then washed and placed in a second microtitre plate containing $100 \mu \mathrm{l}$ of antihuman IgG conjugated with horseradish peroxidase for a further incubation of 30 minutes. The pins are again washed and placed in a third microtitre plate containing $200 \mu$ l of enzyme substrate (o-phenylenediamine-hydrogen chloride in citrate buffer) in each well. This is allowed to react in the dark for 10 minutes and the resultant colour intensity read at $492 \mathrm{~nm}$ after the addition of $4 \mathrm{M} \mathrm{H}_{2} \mathrm{SO}_{4}$. The amount of antibody to dsDNA in the test samples is read off a dose response curve of optical density against antibody concentration present in seven reference sera.

Hemagen Seratest DNA kit (Metachem Diagnostics Ltd, Northampton, England). This is a semiquantitative passive haemagglutination assay (HA). Dilutions $(50 \mu \mathrm{l})$ of heat inactivated serum samples from 1:20 to 1:2560 are placed in appropriate wells of a $\mathrm{V}$ shaped microtitre plate to which is added a suspension of erythrocytes sensitised with native DNA obtained from calf thymus. The plate is then allowed to incubate undisturbed at room temperature for 90 minutes. A positive reaction is seen when agglutination results in the formation of a smooth mat covering the bottom of the microtitre wells. The titre of antibody is taken as the reciprocal of the highest dilution giving a positive reaction.

Anti-native DNA test system (Biodiagnostic Ltd,
Upton upon Severn, England) This is a semiquantitative indirect immunofluorescence technique using Crithidia luciliae. Sera are first diluted from 1/10 to $1 / 320$ and placed on slides containing $C$ luciliae (supplied by Bio-Diagnostics Ltd, Malvern Wells, England for 30 minutes at room temperature. After washing in phosphate buffered saline (PBS) for 20 minutes fluorescein conjugated antihuman globulin (Dako Ltd, High Wycombe, England) is added and the slide reincubated for 30 minutes. The slides are then washed again in PBS, mounted in glycerol saline, and viewed under a fluorescence microsope. The end point titre is taken as the reciprocal of the dilution at which staining of the kinetoplast disappears.

Before the evaluation was started several trial runs were performed using each kit to familiarise the operator with the technique, equipment, and to resolve any difficulties encountered when running the assays.

\section{QUALITY CONTROL SAMPLES}

As some analytes in quality control materials may behave differently from those in specimens from patients a variety of quality control material was tested. For this study it was decided to use the quality control sera from IDS as they were available freeze dried and at low, medium, and high concentrations. The following freeze dried quality control samples were used: (i) the World Health Organisation (WHO), first international standard for anti-dsDNA (Wo/80) at a concentration of $200 \mathrm{IU} / \mathrm{ml}$; (ii) Centers for Disease Control (CDC), reference serum for human antibodies to native DNA at a concentration of $0.59 \mu$ g DNA binding capacity ml; and (iii) sera which contained low, medium, and high dsDNA binding capacity (Immunodiagnostics Services Ltd, Gamma B triple check anti-dsDNA control sera). When the specified amount of distilled water was added to these samples they were regarded as neat sera.

\section{INTERPRETATION OF RESULTS: USE OF}

PERFORMANCE INDEX

Experiments were performed using each kit to determine the characteristics shown below. As various laboratories may have differing views on the relative importance of the performance characteristics, each was assigned a weighting factor from $0-4 ; 0$ being unimportant, 4 being essential. Each characteristic was also given a score on the basis of experimental result; 0 being an unacceptable result, 2 being fully acceptable. In certain circumstances a negative score was given when an exceptionally inadequate performance was found. The sum of the product of the score and weighting factor for each characteristic gave the "performance index" for each kit. The performance index values were then compared. 
The following characteristics were thought to be important for the evaluation of the kits:

1 Precision - within batch and between batch. (Both were given a weighting factor of $\mathbf{4}$ for the quantitative assays and a factor of $\mathbf{2}$ for the semiquantitative assays.)

2 Comparison of results using quality control sera. (weighting factor 2).

3 Dilution study, test for linearity (weighting factor 2).

4 Percentage correct using sera from patients with SLE, RA, and from blood donors (weighting factor 4 for patients with SLE and blood donors and 3 for patients with RA).

5 Interference study (weighting factor 3 ).

6 Subjective impression, including time to result (weighting factor 3 ) and technical difficulty (weighting factor 1).

\section{PRECISION}

Replicate assays were performed on seven sera (five of seven contained anti-DNA antibody activity spanning the analytical range and two of seven were from blood donors). For intrabatch analysis these sera were each assayed 18 times in the same run and the mean, within run standard deviation (SD), and the coefficient of variation (CV) were calculated. For interbatch analysis (day to day precision) the seven sera were assayed on five separate occasions using each kit. Again the mean, between run SD, and $\mathrm{CV}$ were calculated.

\section{COMPARISON OF RESULTS USING QUALITY \\ CONTROL SERA}

The WHO quality control serum WO/80 was first used to recalibrate all the reference standards from the kits into $\mathrm{IU} / \mathrm{ml}$. In the Crithidia test the WHO serum was used directly to standardise the assay. The anti-DNA antibody activities (in $\mathrm{IU} / \mathrm{ml}$ ) in three quality control sera (Gamma B triple check, IDS Ltd) were then measured using the five assays. These values were then compared with the "target value" converted to IU/ml as recommended by the manufacturer. Other quality control sera were also used. As most of these were prediluted or needed to be diluted in a specific diluent before use, however, the results shown are for the IDS samples.

\section{DILUTION STUDIES}

As it is difficult to obtain sufficient quantitities of quality control sera, patient serum samples which gave similar values to the WHO quality control sera when assayed using the quantitative kits were used for this study. Nine sera were diluted in the appropriate diluent as specified by the manufacturer. Dilutions of $5: 6,4: 6,3: 6,2: 6$ and $1: 6$ of the undiluted samples were made. All the samples, including the undiluted sample, were analysed in duplicate. The undiluted sample was regarded as the true value and after correction for the dilution the percentage recovery was calculated from this value.

\section{PATIENTS WITH KNOWN DIAGNOSIS}

The anti-ds DNA activity present in the sera of 45 patients with severe SLE, 41 patients with seropositive $\mathrm{RA}$, and 120 blood donors was determined using each of the five commercial kits. The sera were scored positive or negative according to the manufacturer's normal range. For Amersham International this was 0-25 $\mathrm{U} / \mathrm{ml}$, for Immunodiagnostics 0-5 mg DNA binding capacity $/ 1$, for Walker $0-42 \mathrm{IU} / \mathrm{ml}$. For the haemagglutination and Crithidia immunofluorescence assays positivity was taken if a result at a titre of 10 or over occurred.

\section{INTERFERENCE STUDIES}

Three different substances were added to sera exhibiting a range of anti-DNA antibody activity; the specimens were then assayed using the commercial kits and the per cent increase or decrease calculated. The substances used were: dsDNA at a concentration of $100 \mu \mathrm{g} / \mathrm{ml}$ in PBS, ssDNA at a concentration of $100 \mu \mathrm{g} / \mathrm{ml}$ PBS (ssDNA was obtained by boiling then freezing the dsDNA solution five times), and histones at a concentration of $25 \mathrm{mg} / \mathrm{l}$. All samples were incubated for two hours at room temperature, centrifuged and the supernatant assayed.

\section{SUBJECTIVE IMPRESSION}

During each evaluation the average time from starting the assay until the final result was determined; a note was also made of the operator's impression of each kit which included any difficulties encountered and any desirable features. The price for each test was also calculated for each assay kit. This price was calculated for running the tests in batches and included the incorporation of quality control sera in each batch.

\section{Results}

\section{PRECISION}

In this study we took the CV for RIA and ELISA to be below $15 \%$ and for other assays below $10 \%$. A weighting factor of $\mathbf{4}$ for the quantitative assays and 2 for the semiquantitative assays was given to both the intra- and interrun assay CV. Our scoring was as follows: for the quantitative assays a CV of $0-10 \%$ obtained maximum points-2, a CV of $10-15 \% 1$ point, and a CV of greater than $15 \%$ no points. For the semiquantitative assays a $\mathrm{CV}$ of $0-5 \%$ scored 2 points, $5-10 \% 1$ point, and over $10 \%$ no points. As the intrarun CV for all five kits was acceptable they were 
Table 1 Comparison of intra-and interrun coefficient of variation obtained using five kits studied

\begin{tabular}{llll}
\hline & & \multicolumn{2}{l}{ Coeficient of variation (\%) } \\
\cline { 3 - 4 } Assays & & Intra-run & Inter-run \\
\hline Amersham International & (RIA) & 7.0 & 11.4 \\
IDS & (RIA) & 4.8 & 8.6 \\
Walker & (ELISA) & 9.6 & 11.2 \\
Hemagen & (HA) & 1.6 & 3.7 \\
Crithidia & (IIF) & 2.6 & 4.2 \\
\hline
\end{tabular}

given their maximum scores. The results of the interrun analysis, however, showed only the IDS, Hemagen, and Crithidia assays to have fully acceptable levels (table 1). Both the Amersham International and Walker kits had interrun CV of over $10 \%$ and therefore only obtained a score of 1 .

\section{COMPARISON OF RESULTS USING QUALITY}

CONTROL SERA

Standardisation of the three quality control sera using the WHO and CDC sera showed a range of values when assayed using the five kits. Some of the values were quite different from the manufacturer's target values. The discrepancies between the RIA and ELISA methods were quite pronounced. Table 2 shows the results when the WHO serum was used to standardise the results; a similar result was obtained when the CDC serum was used. Of the five kits, only the results from the IDS and Walker kits were close to the manufacturers' target values. With both standardisation sera (WHO and CDC) the Amersham International kit was reading values nearly twice as high as the target values. A weighting value of 2 was given to this characteristic, only the IDS and Walker kits received a score; the IDS kit scored 1 and the Walker scored 2.

\section{DILUTION STUDIES}

This is a test for linearity. All the kits gave percentage recoveries outside our fully acceptable range of 90 $110 \%$, but the Amersham kit was within the range $80-120 \%$ (table 3). On closer analysis of the results all

Table 2 Comparison of anti-DNA activity in three quality control sera obtained

\begin{tabular}{llcl}
\hline & \multicolumn{3}{l}{$\begin{array}{l}\text { DNA antibody activity (IU/ml) } \\
\text { in quality control sera }\end{array}$} \\
\cline { 2 - 4 } Assays & 1 & 2 & 3 \\
\hline Target value & 23 & 60 & 117 \\
Amersham International & 68 & 187 & 283 \\
IDS & 31 & 93 & 123 \\
Walker & 25 & 65 & 102 \\
Hemagen & 0 & 260 & 320 \\
Crithidia & 0 & 145 & 173 \\
\hline
\end{tabular}

Table 3 Comparison of percentage recoveries obtained using five kits

\begin{tabular}{lc}
\hline Assays & Percentage recovery range \\
\hline Amersham International & $84-117$ \\
IDS & $97-156$ \\
Walker & $72-109$ \\
Hemagen & $105-135$ \\
Crithidia & $105-135$ \\
\hline
\end{tabular}

the kits gave acceptable levels of recovery at 5:6 and 4:6 dilution. Only the IDS kit gave acceptable results at the 3:6 dilution. At the 2:6 and 1:6 dilution the percentage recovery compared with the true value was very poor. This characteristic was given a weighting value of 2; only the Amersham International and IDS kits were given a score of 1 .

\section{PATIENTS WITH KNOWN DIAGNOSIS}

For this study we took the percentage of subjects with abnormal values of dsDNA in their sera to be the following: for patients with severe SLE between 80 and $100 \%^{14}$; for patients with RA a value below $10 \%^{15}$ : and for blood donors $0 \% .{ }^{1}$ The sensitivity (ability to identify correctly patients with a particular disease) using both the HA and the Crithidia assays was unacceptably low-27\% and $53 \%$ of patients with SLE respectively. The specificity (ability to identify correctly patients without the disease) using the Walker kit was also unacceptable; $10 \%$ of blood donors and $33 \%$ of patients with RA gave a positive result (table 4). A weighting factor of 4 was given to the SLE and blood donor group and a value of 3 to the RA group. In the patients with SLE a score of 2 was given if the percentage positivity was greater than $80 \%$, a score of 1 if between 70 and $79 \%$, a nil score for 60 $69 \%$ and a negative score if between 40 and $59 \%$, and a double negative score if below $\mathbf{4 0 \%}$. In the RA group a score of 2 for a value between 0 and $10 \%$, a score of 1 for $11-20 \%$, and a nil score if a value above $20 \%$ were found. In the blood donor group a score of 2 was given if the percentage positivity was between 0 and $4 \%$, a score of 1 if between $5 \%$ and $8 \%$, and a nil score if over $8 \%$. The scores obtained with the three groups are given in table 5 . As the haemagglutination assay gave

Table 4 Percentage of subjects with clinically immportant anti-DNA antibody detected using five kits

\begin{tabular}{llll}
\hline & \multicolumn{3}{l}{ Percentage positivity in patients with } \\
\cline { 2 - 4 } Assays & SLE & $R A$ & Blood donors \\
\hline Amersham International & 96 & 18 & 0 \\
IDS & 83 & 18 & 1 \\
Walker & 91 & 33 & 10 \\
Hemagen & 27 & 8 & 0 \\
Crithidia & 53 & 3 & 0 \\
\hline
\end{tabular}


Table 5 Scoring performance characteristics obtained

\begin{tabular}{|c|c|c|c|c|c|c|}
\hline Performance characteristics & Weighting factor & Amersham International & IDS & Walker & Hemagen & Crithidia \\
\hline $\begin{array}{l}1 \text { Precision } \\
\text { Within } \\
\text { Between } \\
2 \text { Comparison with quality control sera } \\
3 \text { Dilution study } \\
4 \text { Percentage correct } \\
\text { SLE } \\
\text { RA } \\
\text { Blood donors } \\
5 \text { Interference study } \\
6 \text { Subjective impression } \\
\text { Time to result } \\
\text { Technical difficulty } \\
\text { Performance index }\end{array}$ & $\begin{array}{l}4(2)^{*} \\
4(2) \\
2 \\
2 \\
4 \\
3 \\
4 \\
3 \\
3 \\
1 \\
60(56)+\end{array}$ & $\begin{array}{l}8 \\
4 \\
0 \\
2 \\
8 \\
6 \\
8 \\
6 \\
0 \\
1 \\
43\end{array}$ & $\begin{array}{r}8 \\
8 \\
2 \\
2 \\
2 \\
8 \\
8 \\
3 \\
8 \\
3 \\
6 \\
2 \\
50\end{array}$ & $\begin{array}{l}8 \\
4 \\
4 \\
0 \\
8 \\
8 \\
0 \\
0 \\
0 \\
6 \\
2 \\
32\end{array}$ & $\begin{array}{r}4 \\
8 \\
0 \\
0 \\
-8 \\
6 \\
6 \\
8 \\
3 \\
6 \\
6 \\
2 \\
29\end{array}$ & $\begin{array}{r}4 \\
8 \\
0 \\
0 \\
-4 \\
4 \\
6 \\
8 \\
3 \\
6 \\
1 \\
1 \\
32\end{array}$ \\
\hline
\end{tabular}

*Weighting factor for precision characteristics for semiquantitative assays.

†Total marks for the semiquantitative assays.

such a low percentage positivity with the SLE group it was given a score of -2 .

\section{INTERFERENCE STUDY}

The addition of dsDNA to sera considerably reduced the antibody activity measured by all the kits with the exception of the Walker kit in which the activity was only reduced by $37 \%$ (table 6). The addition of denatured DNA also reduced the antibody titres detected by the kits. All were less than that with the addition of dsDNA, except for the Walker kit. Using the isotopic assays the presence of histone increased the measurable antibody titres. A weighting value of 3 was considered to be appropriate for this characteristic. The Amersham International kit came out best with these experiments as only the addition of dsDNA affected the results. This kit was given a score of 2 .

\section{SUBJECTIVE IMPRESSION}

The time to obtain a result ranged from 28 hours with the Amersham International kit to two hours with the Walker kit. The IDS kit took three and a half hours to perform and the two semiquantitative assays two and a half hours. Technically all the kits were relatively easy to use, but the small tubes in the Amersham

Table 6 Comparison of percentage increase or decrease in anti-DNA antibody activity obtained using five kits after addition of various substances

\begin{tabular}{llll}
\hline & \multicolumn{2}{l}{$\begin{array}{l}\text { Percentage increase or decrease with } \\
\text { additional: }\end{array}$} \\
\cline { 2 - 4 } Assays & dsDNA & ssDNA & Histones \\
\hline Amersham International & -84 & -42 & +13 \\
IDS & -68 & -60 & +6 \\
Walker & -37 & -61 & -24 \\
Hemagen & -80 & -60 & -25 \\
Crithidia & -88 & -44 & 0 \\
\hline
\end{tabular}

International kit made handling more awkward, especially at the centrifugation stage. The detection of antibodies to Crithidia kinetoplast was difficult when sera with a high level of non-specific staining was encountered.

\section{PERFORMANCE INDEX}

The scores obtained by each kit with the performance characteristic experiments are shown in table 5 and the performance index values for all the kits in order of highest to lowest are shown in table 7. Although the IDS kit was first, it gained only $83 \%$ of the total marks compared with the Amersham International kit which gained $72 \%$. The other three kits (Crithidia, Walker and Hemagen) each gained a similar percentage of total marks. The price for each sample was roughly the same for all the kits, the Walker kit being the cheapest.

\section{Discussion}

In this study we determined a performance index score for each of five assays for antibodies to dsDNA, according to the criteria suggested by the ECCLS. The highest score was obtained by the kit produced by IDS and the lowest from the kit using the haemagglutination technique. The main reasons why the IDS kit obtained the highest mark were its precision, linearity, sensitivity and specificity for patients with SLE,

Table 7 Comparison of performance indices of five kits together with their price for each test

\begin{tabular}{llll}
\hline & $\begin{array}{l}\text { Performance } \\
\text { index }\end{array}$ & $\begin{array}{l}\text { Percentage of Price per } \\
\text { total marks } \\
\text { test }\end{array}$ \\
\hline 1 IDS & 50 & 83 & $£ 3.95$ \\
2 Amersham International & 43 & 72 & $£ 4.95$ \\
3 Crithidia & 32 & 57 & $£ 4.00$ \\
4 Walker & 32 & 53 & $£ 3.75$ \\
5 Hemagen & 29 & 52 & $£ 4.11$ \\
\hline
\end{tabular}


together with its practicability, although it was not the cheapest test for each sample. Of all the kit assays, none scored very high marks in the evaluation when the percentge of total marks available was determined. Although the two semiquantitative assays scored slightly higher than half the total marks, they did receive a similar percentage of total marks as the Walker kit. It is probably unfair however, to compare these directly with the other quantitative assays.

A major problem with an evaluation of this type is the lack of a plentiful supply of a universal control serum, one that contains dsDNA antibody which is revelant to disease activity. We used control sera from IDS in this study as it was available freeze dried and at three different concentrations but we accept that this choice may have slightly influenced some of our results in favour of the IDS kit. Antibodies to dsDNA are difficult to study and interpret, mainly because of the complexity of the autoimmune response and the unique molecular features of DNA. ${ }^{6}$ It has been suggested that the sera of patients with SLE contain different populations of antibody in respect to avidity, immunoglobulin class, and antigen specificity. Each of the various methods of detection of these antibodies tends to favour one particular population. The Farr technique measures mostly high avidity antibody; the ELISA technique also measures low avidity antibody. The isotopic methods mostly measure IgG antibody, the ELISA and immunofluorescence methods can measure antibodies of different isotypes. ${ }^{78}$

The different methods use different antigens: dsDNA, native DNA, liquid and solid phase antigen. Antibodies to a variety of DNA antigens including dsDNA, native DNA, and ssDNA are found in serum from patients with SLE. ${ }^{6}$ These different antibody populations may be reflected in the differing performance characteristics of each of the five assays used. The question is which is the best antibody population to measure in relation to disease activity? There is a debate as to which antibody population is the most relevant clinically. Various authors have examined the association between the assay result obtained using a variety of different methods and the clinical activity of disease. ${ }^{510}$ From our information on the accuracy or lack of it of these five commercial kits, it would suggest that the correlations with clinical activity may not be totally meaningful.

Another problem is determining the important experiments for the evaluation of such assays, as different laboratories may have different views on the relative importance of the performance characteristics. This has been largely overcome by the use of the performance index scoring system. It would be of considerable value to establish an agreed uniform list of experimental characteristics, weighting factors, and acceptance levels when doing interlaboratory studies. At the time of writing we are still waiting for a definitive test for antibodies to dsDNA, one that is precise, accurate, detects only clinically relevant antibodies to dsDNA, is not inhibited by other constituents and will differentiate patients with SLE from those with similar conditions.

We thank consultant rheumatologists Drs S D Roberts, A J Taggart, and A L Bell for providing the sera of patients with SLE and RA, and Dr T A McNeill for support and criticism.

\section{References}

1 Hughes GRV. Systemic lupus erythematosus. In: Connective tissue diseases. 3rd edition, Oxford. Blackwell Scientific Publications, 1987:48-52.

2 Tan EM, Cohen AS, Fries JF, et al. The 1982 revised criteria for the classification of systemic lupus erythematosus. Arthritis Rheum 1982;25:1271-7.

3 European Committee for Clinical Laboratory Standards. In: Guidelines for a user laboratory to evaluate and select a kit for its own use, Part 1: quantitative tests. ECCLS Vol 3. Berlin: Beuth Verlag, 1986.

4 Eaton RB, Schnneider G, Schur PH. Enzyme immunoassay for antibodies to native DNA. Arthritis Rheum 1983;26:52-62.

5 Isenberg DA, Dudeney C, Williams E, et al. Measurement of antiDNA antibodies: a reappraisal using five different methods. Ann Rheum Dis 1987;46:448-56.

6 Eilat D. Anti-DNA antibodies: problems in their study and interpretation. Clin Exp Immunol 1986;65:215-22.

7 Riley RL, Addis DJ, Taylor RP. Stability of DNA/anti-DNA complexes, II. Salt liability and avidity. J Immunol 1980;124: 1-7.

8 McGrath Jr H, Biundo Jr JJ. A longitudinal study of high and low avidity antibodies to double-stranded DNA in systemic lupus erythematosus. Arthritis Rheum 1985;28:425-30.

9 Esparza HR, Swaak T, Aarden L, Smeenk R. Complement-fixing antibodies to ds DNA detected by the immunofluorescence technique on Crithidia luciliae. A critical appraisal. J Rheumatol 1985;12:1109-17.

10 Clarke MC, Carr R, Burdash NM, Zeyi Chen, Ainsworth SK. A comparison of three anti-double stranded DNA antibody assays on sera from SLE and other diseases. Diagnostic Immunology 1986;4:288-93.

Requests for reprints to: Dr S A McMillan, Region Immunology Laboratory, Belfast City Hospital, Belfast, BT9 7AD, Northern Ireland. 